\title{
INVERTED GAMMA VS. LOG-NORMAL INNOVATIONS IN MSF-SBEKK MODELS \\ IN THE FORECASTING OF SELECTED \\ POLISH EXCHANGE RATES*
}

ŚLĄSKI

PRZEGLĄD

STATYSTYCZNY

Nr 18(24)

ISSN 1644-6739

e-ISSN 2449-9765

\author{
Anna Pajor \\ Cracow University of Economics, Poland, \\ Jagiellonian University in Kraków, Poland \\ e-mails: pajora@uek.krakow.pl; anna.1.pajor@uj.edu.pl \\ ORCID: 0000-0001-5643-0649
}

(C) 2020 Anna Pajor

This work is licensed under the Creative Commons Attribution-ShareAlike 4.0 ternational License. To view a copy of this license, visit http://creativecommons.org/licenses/by-sa/4.0/

Quote as: Pajor, A. (2020). Inverted gamma vs. log-normal innovations in MSF-SBEKK models in the forecasting of selected Polish exchange rates. Ślaski Przeglad Statystyczny, 18(24).

DOI: $10.15611 /$ sps.2020.18.11

\begin{abstract}
The aim of the paper is to compare the forecasting potentials of two classes of Multiplicative Stochastic Factor - scalar BEKK (MSF-SBEKK) models which differ in the type of latent process. In the first class, the innovations of a first order autoregressive structure for the natural logarithm of latent variables are log-normal, whereas in the second class the innovations are inverted gamma distributed. The comparison of the models' forecasting abilities by means of the predictive Bayes factor as well as the log predictive score and energy score were performed based on the Polish exchange rates. The author considered one- to ten-step-ahead predictions during the period beginning from 3 September 2019 and ending on 2 September 2020, which covers the time of the crisis caused by COVID-19. The author concluded that for most of the forecast horizons, the considered log-normal innovations outperformed the inverted gamma ones.
\end{abstract}

Keywords: stochastic volatility model, forecasting, predictive Bayes factor, energy score, log-predictive score.

\section{Introduction}

In volatility modelling of financial time series, two major classes of models are used: the autoregressive conditionally heteroscedastic (ARCH) and stochastic volatility (SV) models. The conceptual difference between the two classes lies in modelling conditional variance. In the ARCH-type

* Research supported by a grant from the National Science Center under decision no. UMO-2018/31/B/HS4/00730. 
models, volatility is described by a deterministic function of the past of the

Nr 18(24) process, whereas in the SV models the conditional variance is subject to unpredictable shocks. In joint modelling of multiple time series the following multivariate counterparts of these models are used: Multivariate GARCH (MGARCH) and Multivariate Stochastic Volatility (MSV) classes (see: Bauwens, Laurent, and Rombouts, 2006); Tsay, 2005). The multivariate approach to modelling financial time series is much more difficult than the univariate one, as it explicitly takes into account the full conditional covariance structure of asset prices, i.e. individual volatilities and correlations. Only a few of them could serve as practical tools for large portfolios. A solution to the problem of multivariate volatility modelling is using the hybrid models proposed by (Osiewalski, 2009) and (Osiewalski and Pajor, 2009, 2018), based on scalar BEKK (SBEKK; Baba, Engle, Kraft, and Kroner, 1989) correlation structure and on one latent process (Multiplicative Stochastic Factor, MSF). The hybrid models exploit the advantages of both model classes: the flexibility of the SV class, where volatility is modeled by latent stochastic processes, and the relative simplicity of the MGARCH class.

The paper focuses on two types of the MSF-SBEKK specification: the LN-MSF-SBEKK and IG-MSF-SBEKK. The LN-MSF-SBEKK structure is obtained by multiplying the SBEKK conditional covariance matrix at time $t, \Sigma_{t}$, by a scalar random variable $g_{t}$ such that $\left\{\ln g_{t}\right\}$ is a Gaussian AR(1) latent process with auto-regression parameter $\varphi$. The LN-MSFSBEKK process can be treated as a direct extension of the SBEKK process with unknown conditional distribution. When $\varphi=0$, the LN-MSFSBEKK process reduces itself to the SBEKK process with the conditional distribution being a continuous mixture of multivariate normal distributions with covariance matrices $\Sigma_{t} g_{t}$, where $g_{t}{ }^{\prime} s$ are independent and log-normally distributed. On the other hand, the multivariate Student $t$ distribution can be expressed as a scale mixture of normal distributions with the inverted gamma (IG) as a mixing distribution. This fact was examined in Osiewalski and Pajor (2018, 2019), where the IG-MSFSBEKK specification was proposed as a natural hybrid extension of the SBEKK process with the Student $t$ conditional distribution ( $t-S B E K K)$. In the IG-MSF-SBEKK specification the latent process $\left\{\ln g_{t}\right\}$ remains an autoregressive process of order one, but with log inverted gamma innovations. For $\varphi=0$ the latent variables $g_{t}$ (where $t \in Z$ ) are independent and have inverted gamma distribution. Thus $\varphi=0$ leads to the t-SBEKK specification, in which the conditional distribution is represented as a continuous mixture of multivariate normal distributions with covariance matrices $\Sigma_{t} g_{t}$ and an inverted gamma distribution of $g_{t}$. For $\varphi \neq 0$ the unconditional distribution of the latent variables $g_{t}$ is 
unknown; moreover, the latent variables $g_{t}(t \in Z)$ are dependent, so there exists an additional source of dependence. The non-Gaussian character of the noise sources can significantly influence the explanatory and predictive power of the hybrid model.

The aim of the paper is to compare the predictive capacity of the two models: LN-MSF-SBEKK and IG-MSF-SBEKK, as well as their reductions to pure SV and SBEKK ones. The data used in our empirical application are daily quotations on three exchange rates: USD/PLN, EUR/PLN and GBP/PLN. These currencies are very important for the Polish economy. The forecasting horizons are from one to ten trading days. The criteria used in this study for drawing this comparison are the predictive Bayes factor, logarithmic score and energy score (see e.g. Geweke, 2005; Geweke and Amisano, 2010; Gneiting and Raftery, 2007).

The paper is organized as follows. In Section 2 Bayesian LN-MSFSBEKK and IG-MSF-SBEKK models are presented. Section 3 is devoted to the predictive Bayes factor and selected scoring rules. Section 4 contains the empirical results, and Section 5 concludes the paper.

\section{The MSF-SBEKK models}

Let us assume that $r_{t}=\left(r_{t, 1}, r_{t, 2}, \ldots, r_{t, n}\right), t=1,2, \ldots, T+H$, be $1 \times n$ vectors of observations (log-returns), which follow the first order vector autoregressive (VAR) structure. Thus VAR(1) can be written:

$$
r_{t}=\delta_{0}+r_{t-1} \Phi_{1}+\varepsilon_{t}, t=1, \ldots, T+H,
$$

where $\delta_{0}$ is $1 \times n$ vector of parameters, $\Phi_{1}$ is $n \times n$ matrix of real coefficients, and $T$ is the length of the observed time series, $H$ is the number of future (forecasted) observations. The hybrid MSF-SBEKK structure for the $1 \times n$ disturbance term $\varepsilon_{t}$ is defined by the following equality:

$$
\varepsilon_{t}=\zeta_{t} \Sigma_{t}^{1 / 2} g_{t}^{1 / 2}
$$

where

$$
\begin{gathered}
\Sigma_{t}=\left(1-\beta_{1}^{2}-\beta_{2}^{2}\right) A+\beta_{1}^{2}\left(\varepsilon_{t-1}^{\prime} \varepsilon_{t-1}\right)+\beta_{2}^{2} \Sigma_{t-1}, \\
\ln g_{t}=\varphi \ln g_{t-1}+\ln \gamma_{t},
\end{gathered}
$$

$\left\{\zeta_{t}\right\} \sim i i N\left(0, I_{n}\right), \zeta_{t} \perp \gamma_{s}$ for all $t, s \in\{1, \ldots, T+H\}, 0<|\varphi|<1$,

$\left\{\zeta_{t}\right\}$ is a Gaussian white noise sequence with the mean vector zero and the unit covariance matrix, $\Sigma_{t}$ is a square matrix of order $n$, symmetric and positive definite for each $t$ and having a scalar BEKK (SBEKK) form, $\left\{g_{t}\right\}$ 
is a scalar stochastic latent process, $\left\{\gamma_{t}\right\}$ is a sequence of independent positive random variables, $\beta_{1}$ and $\beta_{2}$ are real numbers satisfying the inequality $\beta_{1}^{2}+\beta_{2}^{2}<1$, the notation $\zeta_{t} \perp \gamma_{s}$ denotes that random variables $\zeta_{t}$ and $\gamma_{s}$ are independent. Furthermore, the process defined by (1)-(5) contains initial conditions $g_{0}, r_{0}=\left(r_{-1,1}, \ldots, r_{-1, n}, r_{0,1}, \ldots, r_{0, n}\right)$ and $\Sigma_{0}$ of $g_{t}, r_{t}$ and of $\Sigma_{t}$, respectively.

In the IG-MSF-SBEKK process, $\gamma_{t}$ is inverted gamma distributed with mean $\frac{v}{v-2}$ for $v>2$, that is $\left\{\gamma_{t}\right\} \sim \operatorname{iiI} G\left(\frac{v}{2}, \frac{v}{2}\right)$, whereas in the LN-MSFSBEKK process $\gamma_{t}$ is $\log$ normal distributed with mean $e^{\frac{1}{2} \sigma^{2}}$ and variance $\left(e^{\sigma^{2}}-1\right) e^{\sigma^{2}}$, in other words $\left\{\ln \gamma_{t}\right\} \sim i i N\left(0, \sigma^{2}\right)$.

Under (1) to (5), the conditional distribution of $r_{t}$ (given the past of $r_{t}$ and the current latent variable $g_{t}$ ) is determined by the distribution of $\zeta_{t}$. Therefore, given the past of $r_{t}$ and the current latent variable $g_{t}, r_{t}$ has the normal distribution with the mean vector $\mu_{t}=\delta_{0}+r_{t-1} \Phi_{1}$ and the covariance matrix $g_{t} \Sigma_{t}$. In turn, the distribution of $r_{t}$ given only its past is the scale mixture of $N\left(\mu_{t}, g_{t} \Sigma_{t}\right)$. In the case of the LN-MSF specification, the marginal distribution of $g_{t}$ is log-normal. In the IG-MSF specification this marginal distribution is unknown. However, for $\varphi=0 g_{t}=\gamma_{t}$, hence the distribution of $g_{t}$ is inverted gamma. Consequently, $\varphi=0$ leads to the SBEKK process with conditional Student $t$ distribution. Thus one can view the IG-MSF-SBEKK structure as a natural hybrid extension of the popular tSBEKK specification. It is worth mentioning that in the LN-MSF-SBEKK process, $\varphi=0$ also leads to the SBEKK process, but with an unknown conditional distribution.

The Bayesian statistical model amounts to specifying the joint distribution of all observations, latent variables and parameters. The assumptions presented so far determine the conditional distribution of the vector of observations and the vector of latent variables given the parameters. Therefore, what remains to be done is to formulate the marginal distribution of the parameters (the prior distribution). The author assumed independence among the groups of parameters and used the following prior distributions (cf. Osiewalski and Pajor, 2019; Pajor and Wróblewska, 2017)²:

${ }^{1}$ The following symbols are used:

$f_{m N}(x \mid M, U, V)$ - the probability density function of the matrix normal distribution with mean $M$, and positive definite matrices $U$ and $V$,

$f_{I G}(x \mid a, b)$ - the probability density function of the inverted gamma distribution with mean $b /(a-1)$ for $a>1$,

$f_{I W}(x \mid V, q)$ - the probability density function of the inverse Wishart distribution with $p \times p$ scale matrix $V$ and $q$ degrees of freedom,

$f_{N}(x \mid a, b)$ - the probability density function of the normal distribution with mean $a$ and variance $b$,

$f_{G}(x \mid a, b)$ - the probability density function of the gamma distribution with mean $\frac{a}{b}$, 
- the multivariate $t$ distribution for $\delta=\left[\delta_{0} \Phi_{1}\right]: \quad p\left(\delta \mid \sigma_{\delta}^{2}\right)=$ $f_{m N}\left(\delta \mid 0, I_{n}, \sigma_{\delta}^{2} I_{n+1}\right)$ with inverted gamma distribution for $\sigma_{\delta}^{2}: p\left(\sigma_{\delta}^{2}\right)=$ $f_{I G}\left(\sigma_{\delta}^{2} \mid 3,2\right), \quad E\left(\sigma_{\delta}^{2}\right)=1, V\left(\sigma_{\delta}^{2}\right)=1, \quad V\left(\operatorname{vec}(\delta) \mid \sigma_{\delta}^{2}\right)=I_{n} \otimes$ $\sigma_{\delta}^{2} I_{n+1}=\sigma_{\delta}^{2} I_{n^{2}+n}$, thus $E(\delta)=0, V(\operatorname{vec}(\delta))=I_{n^{2}+n}$,

- the inverse Wishart distribution for $A: p(A)=f_{I W}\left(\mathrm{~A} \mid I_{n}, n+2\right)$, so $E(\mathrm{~A})=I_{n}$,

- the normal distribution for $\varphi$, truncated by the restriction $|\varphi|<1$ : $p(\varphi) \propto f_{N}(\varphi \mid 0,100) I_{(-1,1)}(\varphi)$,

- the inverted gamma distribution for $\sigma^{2}: p\left(\sigma^{2}\right)=f_{I G}\left(\sigma^{2} \mid 2.5,0.16\right)$, so $E\left(\sigma^{2}\right) \approx 0.107$

- the gamma distribution for $v: p(v)=f_{G}(v \mid 3,0.1)$, so $E(v) \approx 30$, $\operatorname{Mode}(v) \approx 20$,

- the uniform distribution over the unit square $[0,1]^{2}$ for $\beta_{1}$ and $\beta_{2}$, truncated by the restriction $\beta_{1}^{2}+\beta_{2}^{2}<1: p\left(\beta_{1}, \beta_{2}\right) \propto I_{(0,1)}\left(\beta_{1}^{2}+\beta_{2}^{2}\right)$,

- the exponential distribution for $\sigma_{0}: p\left(\sigma_{0}^{2}\right)=f_{\operatorname{Exp}}\left(\sigma_{0}^{2} \mid 1\right)$, so $E\left(\sigma_{0}^{2}\right)=1$. The prior distributions reflect little prior knowledge about the model parameters. As regards initial conditions for $\Sigma_{t}$, we take $\Sigma_{0}=\sigma_{0}^{2} I_{n}$ and treat $\sigma_{0}^{2}>0$ as an additional parameter, exponentially distributed a priori with mean 1, whereas the initial value of $g_{t}, g_{0}$, is assumed to be nonrandom and equal to 1 . When it comes to $r_{0}$, the first two vectors of observations are used as initial conditions for $r_{t}$.

\section{Forecast evaluation}

The standard approach to the Bayesian forecast evaluation is based on the predictive likelihood - the predictive data density value at the observed future data. Let $r_{0}^{T}=\left(r_{0}, r_{1}, \ldots, r_{T}\right)$ be the vector of observations up to time $T, \theta$ be the vector of unknown parameters and $g_{1}^{T+h}=\left(g_{1}, \ldots, g_{T+h}\right)$ the latent variable vector. The predictive density function for $h$-step-ahead forecast is as follows:

$$
p\left(r_{T+h} \mid r_{0}^{T}\right)=\int p\left(r_{T+h} \mid r_{0}^{T}, g_{1}^{T+h}, g_{0}, \theta\right) p\left(g_{1}^{T+h}, \theta \mid r_{0}^{T}, g_{0}\right) d g_{1}^{T+h} d \theta,
$$

where $p\left(r_{T+h} \mid r_{0}^{T}, g_{1}^{T+h}, g_{0}, \theta\right)$ is the conditional density of the future observation vector given the vector of parameters, $\theta$, and latent variables, $g_{1}, \ldots, g_{T+h} ; p\left(g_{1}^{T+h}, \theta \mid r_{0}^{T}, g_{0}\right)$ is the posterior probability density function of parameters and latent variables at time $T$. Let $r_{0}^{T, o}$ and $r_{T+h}^{O}$

$f_{E x p}(x \mid \lambda)$ - the probability density function of the exponential distribution with mean $\frac{1}{\lambda}$, $I_{(\mathrm{a}, \mathrm{b})}(x)-$ the indicator function of the interval $(a, b)$. 
denote observed values of $r_{0}^{T}$ and $r_{T+h}$, respectively. The predictive Nr 18(24) likelihood conditional on $r_{0}^{T, o}$ is the real number $p\left(r_{T+h}^{o} \mid r_{0}^{T, o}\right)$. To compute this predictive likelihood we draw $g_{1}^{T+h,(i)}, \theta^{(i)}$ for $i=1, \ldots, N$ from the posterior distribution, next, if $h>1$, simulate the vector $r_{T+1}^{T+h-1,(i)}$ from conditional sampling distribution of observations given $r_{0}^{T, o}, g_{1}^{T+h,(i)}$ and $\theta^{(i)}$, and then calculate the average:

$$
\begin{gathered}
\hat{p}\left(r_{T+h}^{o} \mid r_{0}^{T}\right)=\frac{1}{N} \sum_{i=1}^{N} p\left(r_{T+h}^{o} \mid r_{0}^{T, o}, r_{T+1}^{T+h-1,(i)}, g_{1}^{T+h,(i)}, g_{0}, \theta^{(i)}\right) \\
\text { for } h>1,
\end{gathered}
$$

or

$$
\hat{p}\left(r_{T+1}^{o} \mid r_{0}^{T}\right)=\frac{1}{N} \sum_{i=1}^{N} p\left(r_{T+1}^{o} \mid r_{0}^{T, o}, g_{1}^{T+1,(i)}, g_{0}, \theta^{(i)}\right) \text { for } h=1 .
$$

Let us assume that there are two competing models: $M_{i}$ and $M_{j}$. Then the main Bayesian criterion of model comparison from the predictive point of view is the predictive Bayes factor, which is the ratio of the predictive likelihoods. In fact the posterior odds ratio can be expressed as the product of the predictive Bayes factor and the posterior odds ratio given the observed data $r_{0}^{T, o}$ :

$$
\frac{p\left(M_{i} \mid r_{T+h}^{o}, r_{0}^{T, o}\right)}{p\left(M_{j} \mid r_{T+h}^{o}, r_{0}^{T, o}\right)}=\frac{p\left(r_{T+h}^{o} \mid r_{0}^{T, o}, M_{i}\right)}{p\left(r_{T+h}^{o} \mid r_{0}^{T, o}, M_{j}\right)} \frac{p\left(M_{i} \mid r_{0}^{T, o}\right)}{p\left(M_{j} \mid r_{0}^{T, o}\right)} .
$$

Thus, the predictive Bayes factor:

$$
B_{i j}\left(r_{T+h}^{o} \mid r_{0}^{T, o}\right)=\frac{p\left(r_{T+h}^{o} \mid r_{0}^{T, o}, M_{i}\right)}{p\left(r_{T+h}^{o} \mid r_{0}^{T, o}, M_{j}\right)}
$$

updates the ratio of posterior probabilities based on the first $T$ observations after observing predicted data $r_{T+h}^{O}$. It is well-known that the negative log predictive likelihood, $-\log p\left(r_{T+h}^{O} \mid r_{0}^{T}\right)$, is the logarithmic score (log score) for the predictive distribution at observation $r_{T+h}^{o}$ (see: Bernardo and Smith, 1994; Dawid and Musio, 2014). Thus the logarithm of the Bayes factor is the difference of the log scores for the two models:

$$
\log B_{i j}\left(r_{T+h}^{o} \mid r_{0}^{T, o}\right)=\log p\left(r_{T+h}^{o} \mid r_{0}^{T, o}, M_{i}\right)-\log p\left(r_{T+h}^{o} \mid r_{0}^{T, o}, M_{j}\right) .
$$

The logarithm of the Bayes factor measures by how much the log score for model $M_{i}$ is better (smaller) than that for model $M_{j}$ (see: Dawid and Musio, 2015). The value of $\log B_{i j}\left(r_{T+h}^{o} \mid r_{0}^{T, o}\right)<0$ indicates the poor forecasting performance of model $M_{i}$ at time $T$ for the $h$-step-ahead 
forecast in comparison to model $M_{j}$. The $\log p\left(r_{T+h}^{o} \mid r_{0}^{T, o}, M_{i}\right)$ returns a high value if $r_{T+h}^{o}$ is in the high density region of $p\left(r_{T+h} \mid r_{0}^{T, o}, M_{i}\right)$, and a low value otherwise. The drawback of the log score is that it does not depend directly on the shape of the entire predictive density, but only on the value of the predictive density at the realized value of $r_{T+h}$.

To compare the forecasting ability of the models under consideration for the forecast horizon $h$, in the period from $T+1$ to $T+H_{h}$ (where $H_{h}$ represents the number of $h$-step-ahead forecasts, $H_{h} \leq H$ ), we aggregate $\log$ scores and rank models by the average of the logarithms of the predictive likelihoods:

$S\left(h, T+1, T+H_{h}, M_{i}\right)=\frac{1}{H_{h}} \sum_{t=T+1}^{T+H_{h}} \log p\left(r_{t+h-1}^{o} \mid r_{0}^{t-1, o}, M_{i}\right)$.

The $S\left(h, T+1, T+H_{h}, M_{i}\right)$ is a positively oriented score, which means that its larger values indicate more accurate density forecasts (in other words, larger values of this score are better). Unfortunately, the logarithmic scoring rule is sensitive to outliers.

Note that for $h=1 S\left(1, T+1, T+H_{1}, M_{i}\right)=\frac{1}{H_{1}} \log p\left(r_{T+1}^{o}, \ldots\right.$, $\left.r_{T+H_{1}}^{o} \mid r_{0}^{T, o}, M_{i}\right)$ thus the average of the log predictive density scores times the length of forecasting period amounts to the predictive likelihood of the observed data from $T+1$ to $T+H_{1}$. This is so because the log predictive likelihood at $r_{T+1}^{o}, \ldots, r_{T+H_{1}}^{o}$, can be rewritten as a sum of one-step-ahead log predictive likelihoods:

$$
\log p\left(r_{T+1}^{o}, \ldots, r_{T+H_{1}}^{o} \mid r_{0}^{T, o}, M_{i}\right)=\sum_{k=1}^{H_{1}} \log p\left(r_{T+k}^{o} \mid r_{0}^{T+k-1, o}, M_{i}\right) .
$$

Consequently, for $h=1$ there exists a Bayesian substantiation of the use of the sum of logarithmic scores. Equality (12) breaks down for $h>1$. The predictive density at $r_{T+h}^{O}, \ldots, r_{T+H_{h}}^{O}$ cannot be decomposed in terms of the $h$-step-ahead predictive likelihoods. Moreover, some models can perform well for certain forecast horizons while other models can be better for other horizons.

In the paper the author also used the energy score (ES), recommended for assessing the multidimensional predictive density (see e.g. Gneiting and Raftery, 2007; Székely and Rizzo, 2013). Let us assume that $P_{T, T+h}$ denotes the predictive distribution for $r_{T+h}$ given the data up to time $T$. The energy score is defined as:

$$
E S\left(P_{T, T+h}, r_{T+h}^{o}\right)=E_{P_{T, T+h}}\left\|X-r_{T+h}^{o}\right\|^{\beta}-\frac{1}{2} E_{P_{T, T+h}}\|X-Y\|^{\beta},
$$

where $\beta \in(0,2), X$ and $Y$ are independent random vectors with distribution $P_{T, T+h}$, and $\|\cdot\|$ denotes the Euclidean norm. 
To estimate the energy score, we use the following formula:

Nr 18(24)

$$
\begin{gathered}
\widehat{E S}\left(P_{T, T+h}, r_{T+h}^{o}\right)=\frac{1}{m} \sum_{i=1}^{m}\left\|x^{(i)}-r_{T+h}^{o}\right\|^{\beta}- \\
\frac{1}{2 \mathrm{~m}^{2}} \sum_{j=1}^{m} \sum_{i=1}^{m}\left\|x^{(i)}-y^{(j)}\right\|^{\beta},
\end{gathered}
$$

where $x^{(i)}$ and $y^{(j)}$ are drawn from predictive distribution of $r_{T+h}$, using the MCMC methods presented in (Osiewalski and Pajor, 2009; Pajor, 2020). In this paper $E S$ is applied with $\beta=1$, and it is aggregated over $T$, $\ldots, T+H_{h}-1$ :

$$
\overline{E S}_{T, h}^{T+H_{h}-1}=\frac{1}{H_{h}} \sum_{t=T}^{T+H_{h}-1} \widehat{E S}\left(P_{t, t+h}, r_{t+h}^{o}\right) .
$$

The average energy score is used to rank (of course informally from the Bayesian point of view) competing models.

\section{Empirical results}

In this part of the paper the author analysed financial data of daily quotations on three major Polish exchange rates: the EURO to the Polish zloty (EUR/PLN), the US dollar to Polish zloty (USD/PLN), and the British pound to the Polish zloty (GBP/PLN, all data were downloaded from http://stooq.com). The daily currency return data used in this study cover the period from 28 December 2017 to 2 September 2020 (see Figures 1 and 2). The dataset of the growth rates of the exchange rates consists of 693 observations (for each series). The first two observations were treated as an initial condition, while the last 237 observations were used for the forecast evaluation, thus $T=456$. In other words, to compare the predictive capacity of the models under consideration, the author used these first 456 observations as a training sample. The predictive capacity of the models was analysed in the most recent 237 trading days $(H=237)$. The author took into consideration one- to ten-step-ahead predictions during the period beginning on 3 October 2019 and ending on 2 September 2020, thus obtaining 228 predictive distributions for the one- to ten-dayahead forecast horizons. The predictive distributions were calculated based on the whole dataset available at time $T+t$ for each $t=0,1, \ldots, H-10$. This resulted in 2280 estimated predictive distributions. The sequence of the one-step-ahead predictive distributions covers the period from 3 October 2019 to 20 August 2020, while the sequence of the ten-stepahead predictive distributions covers the period 16 October 20192 September 2020. 
Moreover, the forecasting period was split using 12 March 2020 as the dividing point. The first subperiod (3 October 2019-11 March 2020) is characterized by the relatively (as compared to the second subperiod) low STATYSTYCZNY volatility of the forecasted exchange rates, whereas the second subperiod (12 March 2020-2 September 2020) contains the time of the crisis caused by the COVID-19 pandemic (the first incidence of COVID-19 was reported by the Polish authorities on 4 March 2020, and the lockdown-type control measures started on 12 March). Due to the coronavirus (COVID-19) and lockdown, significant turbulences and high volatility were observed, especially at the beginning of the pandemic lockdown period (see Figures 1 and 2).

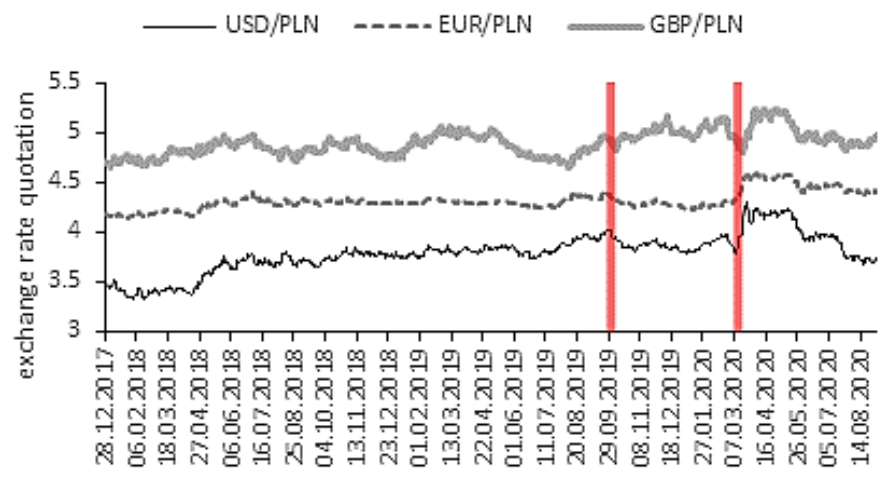

Fig. 1. Daily quotations on exchange rates. The first vertical (red) line represents 3 September 2019 (the beginning of the forecasting period), the second one represents 12 March 2020 (when lockdown-type control measures were first implemented in Poland)

Source: calculated by the author (based on data from www.stooq.com).
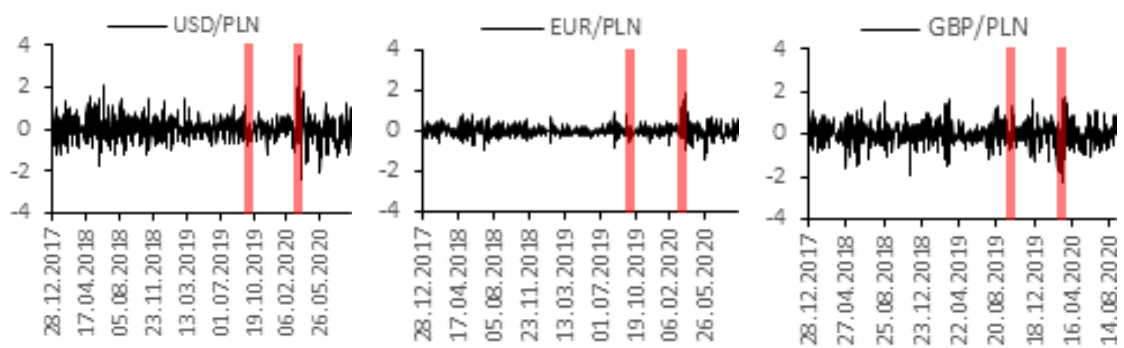

Fig. 2. Logarithmic daily growth rates of USD/PLN, EUR/PLN and GBP/PLN (in percentage points). The first vertical (red) line represents the beginning of the prediction period (3 September 2019), the second one represents 12 March 2020

Source: calculated by the author (based on data from www.stooq.com). 
As one can see from Figures 1 and 2, the EURO growth rates series seems to have the lowest volatility. The exchange rate series of USD/PLN appears to be the most volatile. The USD/PLN exchange rate strengthened to 4.29327 on 23 March 2020 from 3.87587 on 2 March 2020, and next fell below 3.6900 on 28 August 2020. A similar (but not the same) pattern during the forecasting period is observed in the plot of the GBP/PLN exchange rate. During the second predictive subperiod, relatively large fluctuations in all the exchange rates considered were observed. Thus it was possible to check how the outliers affect the predictive ability of the (MSF-)SBEKK models.

The VAR(1)-MSF-SBEKK models were re-estimated at a daily frequency. The computations are based on the 30000 Markov chain Monte Carlo posterior samples after having burnt 50000 cycles in each model.

\subsection{A comparison of models with the predictive Bayes factor}

As mentioned above, the author considered two basic specifications of the MSF-SBEKK models, LN-MSF-SBEKK and IG-MSF-SBEKK. Additionally, there are two natural reductions of the two hybrid models to SBEKK specifications, LN-SBEKK and IG-SBEKK (t-SBEKK), which result from imposing a zero restriction on $\varphi$. Moreover, there are two reductions to pure MSF specifications, LN-MSF and IG-MSF, which result from imposing zero restrictions on $\beta_{1}$ and $\beta_{2}$. For the sake of comparison, the study also considered the VAR model with constant conditional covariance matrix, despite the fact that this model seems to be inadequate for the type of the data considered. The model assumptions are presented in Table 1.

Table 1. The model assumptions

\begin{tabular}{|c|c|}
\hline Model & $\begin{array}{l}\text { Description of process }\left\{\varepsilon_{t}\right\} \text { : } \\
\varepsilon_{t}=\zeta_{t} \Sigma_{t}^{1 / 2} g_{t}^{1 / 2}, t=1, \ldots, T+H\end{array}$ \\
\hline LN-MSF-SBEKK & $\begin{array}{l}\Sigma_{t}=\left(1-\beta_{1}^{2}-\beta_{2}^{2}\right) A+\beta_{1}^{2}\left(\varepsilon_{t-1}^{\prime} \varepsilon_{t-1}\right)+\beta_{2}^{2} \Sigma_{t-1}, \ln g_{t}= \\
\varphi \ln g_{t-1}+\ln \gamma_{t},\left\{\boldsymbol{l n} \gamma_{t}\right\} \sim \boldsymbol{i} \boldsymbol{i N}\left(\mathbf{0}, \boldsymbol{\sigma}^{2}\right)\end{array}$ \\
\hline IG-MSF-SBEKK & $\begin{array}{l}\Sigma_{t}=\left(1-\beta_{1}^{2}-\beta_{2}^{2}\right) A+\beta_{1}^{2}\left(\varepsilon_{t-1}^{\prime} \varepsilon_{t-1}\right)+\beta_{2}^{2} \Sigma_{t-1}, \ln g_{t}= \\
\varphi \ln g_{t-1}+\ln \gamma_{t},\left\{\gamma_{t}\right\} \sim \boldsymbol{i i I G}(\boldsymbol{v} / \mathbf{2}, \boldsymbol{v} / \mathbf{2})\end{array}$ \\
\hline LN-SBEKK & $\begin{array}{l}\Sigma_{t}=\left(1-\beta_{1}^{2}-\beta_{2}^{2}\right) A+\beta_{1}^{2}\left(\varepsilon_{t-1}^{\prime} \varepsilon_{t-1}\right)+\beta_{2}^{2} \Sigma_{t-1}, \ln g_{t}= \\
\ln \gamma_{t},\left\{\boldsymbol{l n} \gamma_{t}\right\} \sim \boldsymbol{i} \boldsymbol{i} \boldsymbol{N}\left(\mathbf{0}, \boldsymbol{\sigma}^{2}\right)\end{array}$ \\
\hline $\begin{array}{l}\text { IG-SBEKK } \\
(\mathrm{t}-\mathrm{SBEKK})\end{array}$ & $\begin{array}{l}\Sigma_{t}=\left(1-\beta_{1}^{2}-\beta_{2}^{2}\right) A+\beta_{1}^{2}\left(\varepsilon_{t-1}^{\prime} \varepsilon_{t-1}\right)+\beta_{2}^{2} \Sigma_{t-1}, \ln g_{t}= \\
\ln \gamma_{t},\left\{\boldsymbol{\gamma}_{\boldsymbol{t}}\right\} \sim \boldsymbol{i i I G}(\boldsymbol{v} / \mathbf{2}, \boldsymbol{v} / \mathbf{2})\end{array}$ \\
\hline LN-MSF & $\Sigma_{t}=A, \ln g_{t}=\varphi \ln g_{t-1}+\ln \gamma_{t},\left\{\boldsymbol{l n} \gamma_{t}\right\} \sim \boldsymbol{i i N}\left(\mathbf{0}, \boldsymbol{\sigma}^{2}\right)$ \\
\hline IG-MSF & $\Sigma_{t}=A, \ln g_{t}=\varphi \ln g_{t-1}+\ln \gamma_{t},\left\{\boldsymbol{\gamma}_{t}\right\} \sim \boldsymbol{i i I G}(\boldsymbol{v} / \mathbf{2}, \boldsymbol{v} / \mathbf{2})$ \\
\hline VAR & $\Sigma_{t}=A, g_{t}=1$ \\
\hline
\end{tabular}

Source: author's elaboration. 
Table 2. The log predictive Bayes factors in favour of the LN-MSF-SBEKK model $\left(M_{1}\right)$, obtained for the whole forecasting period and for two subperiods

\begin{tabular}{|l|c|c|c|}
\hline \multirow{2}{*}{ Model } & \multicolumn{3}{|c|}{ Log-predictive Bayes factor } \\
\cline { 2 - 4 } & $\begin{array}{c}\text { 3 September 2019- } \\
\text { 20 August 2020 }\end{array}$ & $\begin{array}{c}\text { 3 September 2019- } \\
\text { 11 March 2020 }\end{array}$ & $\begin{array}{c}\text { 12 March 2020- } \\
\text { 20 August 2020 }\end{array}$ \\
\hline $\begin{array}{l}\text { LN-MSF- } \\
\text { SBEKK }\end{array}$ & 0 & 0 & 0 \\
\hline $\begin{array}{l}\text { IG-MSF- } \\
\text { SBEKK }\end{array}$ & 15.256 & 5.442 & 9.814 \\
\hline LN-SBEKK & 17.018 & 2.249 & 14.769 \\
\hline $\begin{array}{l}\text { IG-SBEKK } \\
\text { t-SBEKK) }\end{array}$ & 16.122 & 2.071 & 14.051 \\
\hline LN-MSF & 2.037 & 2.702 & -0.665 \\
\hline IG-MSF & 2.684 & 3.028 & -0.343 \\
\hline VAR & 53.915 & 10.490 & 43.425 \\
\hline
\end{tabular}

Source: calculated by the author.

Table 2 presents the decimal logarithms of the predictive Bayes factors for the whole forecasting period $(T+1, \ldots, T+228)$ and for two subperiods $(T+1, \ldots, T+113$ and $T+114, \ldots, T+228)$ in favour of the LN-MSF-SBEKK model $\left(M_{1}\right)$ versus the other models under consideration. The predictive Bayes factors (the preferred method of the Bayesian forecast comparison) presented in Table 2 show how the additional data (the whole path of observed future data in each period considered) influenced the posterior probability of the LN-MSF-SBEKK model relative to all the specifications under consideration. As one can see from Table 2, the LN-MSF-SBEKK model fits the data (in terms of the predictive Bayes factor) much better than the IG-MSF-SBEKK one. The predictive power of the LN-MSF-SBEKK model within the whole period $T+1, \ldots, T+228$ (3 September 2019-20 August 2020) and within the first subperiod (3 September 2019-11 March 2020) dominates all the models considered. A different result was obtained for the lockdown period (12 March 2020-20 August 2020). Surprisingly, the LN-MSF model turned out to be the best from the predictive point of view. The predictive performance of the LN-MSF model dominates other models. In fact, the negative value of $\log B_{1 i}\left(r_{T+115}^{T+228, o} \mid r_{0}^{T, o}\right)$ means that this relative posterior probability of the LN-MSF-SBEKK model decreases. The IG-MSF model took second place, while the LN-MSF-SBEKK ranked third. However, the log-predictive Bayes factors in favour of the LN-MSF-SBEKK specification over the LN-MSF and IG-MSF ones are less than one (in absolute terms) each, and thus, according to the scale presented by (Kass and Raftery, 1995), it is only a positive (not strong) evidence against the 
LN-MSF-SBEKK model. In general, as indicated by predictive Bayes factors, lognormal innovations in MSF-SBEKK and MSF structures lead to greater predictive capacity compared with the same structures based on inverted gamma innovations.

The predictive Bayes factors provided very strong evidence in favour of the LN-MSF-SBEKK specification against the IG-MSF-SBEKK one in the three forecasting periods considered. For the whole forecasting period, 3 September 2019 to 20 August 2020, the decimal logarithm of the predictive Bayes factor in favour of the LN-MSF-SBEKK model against the IG-MSF-SBEKK model $\left(M_{2}\right)$ was close to 15 , which indicates that the posterior odds ratio based on the first $T=456$ observations $\left(p\left(M_{1} \mid r_{0}^{T, o}\right) /\right.$ $\left.p\left(M_{2} \mid r_{0}^{T, o}\right)\right)$ increased by about 15 orders of magnitude after observing predicted data $r_{T+1}^{T+228, o}$. The increase of the posterior odds ratio was higher for the second subperiod (the lockdown period) by about 10 orders of magnitude. While comparing two pure SV specifications (the LN-MSF and the IG-MSF), the author concluded that log-normal innovations in the latent process were preferred by each additional set of data: $r_{T+1}^{T+228, o}, r_{T+1}^{T+113, o}$ and $r_{T+114}^{T+228, o}$. The opposite conclusion can be reached if one compares the two pure SBEKK specifications. The SBEKK model with conditional Student $t$ distribution is better from the predictive point of view than the LN-SBEKK one. It seems that the SBEKK structure is less flexible in dealing with outliers, and therefore it requires a conditional distribution with thicker tails. Obviously, the last position is occupied by the VAR model with constant conditional covariances.

\subsection{Forecast evaluation with the log-predictive score and energy score}

This section presents the results of comparing the predictive ability of the considered Bayesian models with the use of non-Bayesian tools. Tables 3 to 5 present the average log-predictive scores along with their respective ranks. The first conclusion from Tables 3 to 5 is that the LN-MSF-SBEKK model produced the best forecasts for all the considered forecast horizons and for all the forecasting periods considered, except for $h=1$ in the lockdown period (11 March 2020-2 September 2020), for which the LN-MSF model turned out to be the best. Moreover, for the whole period $T+h, \ldots, T+228+h$ (3 September 2019-2 September 2020) and for the second subperiod (11 March 2020-2 September 2020) the first four positions in the ranks are occupied by the LN-MSF, IG-MSF, LN-MSFSBEKK, and IG-MSF-SBEKK models. Thus, the second conclusion was that the presence of a latent process with dependent latent variables is more 
important than allowing for the pure SBEKK structure. Both the LNSBEKK and IG-SBEKK models, which do not use any latent autoregressive processes and therefore are less flexible in dealing with STATYSTYYZNY outliers, appeared as the worst among conditional heteroscedastic models in terms of the average log-predictive score.

Table 3. The average log predictive scores and ranks obtained for the whole forecasting period 3 September2019-2 September 2020

\begin{tabular}{|l|c|c|c|c|c|c|c|c|c|c|}
\hline \multicolumn{1}{|c|}{ Model } & $h=1$ & rank & $h=2$ & rank & $h=3$ & rank & $h=4$ & rank & $h=5$ & rank \\
\hline $\begin{array}{l}\text { LN-MSF- } \\
\text { SBEKK }\end{array}$ & $\mathbf{- 0 . 6 5 8}$ & $\mathbf{1}$ & $\mathbf{- 1 . 1 2 2}$ & $\mathbf{1}$ & $\mathbf{- 1 . 4 0 1}$ & $\mathbf{1}$ & $\mathbf{- 1 . 5 9 3}$ & $\mathbf{1}$ & $\mathbf{- 1 . 7 4 7}$ & $\mathbf{1}$ \\
\hline $\begin{array}{l}\text { IG-MSF- } \\
\text { SBEKK }\end{array}$ & -0.725 & 4 & -1.202 & 4 & -1.453 & 4 & -1.652 & 4 & -1.817 & 4 \\
\hline LN-SBEKK & -0.733 & 6 & -1.217 & 6 & -1.499 & 6 & -1.708 & 6 & -1.893 & 6 \\
\hline $\begin{array}{l}\text { IG-SBEKK } \\
\text { (t-SBEKK) }\end{array}$ & -0.729 & 5 & -1.209 & 5 & -1.490 & 5 & -1.705 & 5 & -1.864 & 5 \\
\hline LN-MSF & -0.667 & 2 & -1.141 & 2 & -1.417 & 2 & -1.618 & 2 & -1.773 & 2 \\
\hline IG-MSF & -0.668 & 3 & -1.142 & 3 & -1.419 & 3 & -1.623 & 3 & -1.778 & 3 \\
\hline VAR & -0.894 & 7 & -1.421 & 7 & -1.782 & 7 & -2.078 & 7 & -2.410 & 7 \\
\hline \hline \multicolumn{1}{|c|}{ Model } & $h=6$ & rank & $h=7$ & rank & $h=8$ & rank & $h=9$ & rank & $h=10$ & rank \\
\hline $\begin{array}{l}\text { LN-MSF- } \\
\text { SBEKK }\end{array}$ & $-\mathbf{1 . 8 8 3}$ & $\mathbf{1}$ & $\mathbf{- 2 . 0 0 5}$ & $\mathbf{1}$ & $\mathbf{- 2 . 1 1 7}$ & $\mathbf{1}$ & $\mathbf{- 2 . 2 0 2}$ & $\mathbf{1}$ & $\mathbf{- 2 . 2 7 3}$ & $\mathbf{1}$ \\
\hline $\begin{array}{l}\text { IG-MSF- } \\
\text { SBEKK }\end{array}$ & -1.992 & 4 & -2.103 & 4 & -2.232 & 4 & -2.336 & 4 & -2.399 & 4 \\
\hline LN-SBEKK & -2.102 & 6 & -2.247 & 6 & -2.410 & 6 & -2.527 & 6 & -2.621 & 6 \\
\hline $\begin{array}{l}\text { IG-SBEKK } \\
\text { (t-SBEKK) }\end{array}$ & -2.035 & 5 & -2.203 & 5 & -2.293 & 5 & -2.467 & 5 & -2.556 & 5 \\
\hline LN-MSF & -1.928 & 2 & -2.054 & 2 & -2.172 & 2 & -2.265 & 2 & -2.334 & 2 \\
\hline IG-MSF & -1.937 & 3 & -2.061 & 3 & -2.190 & 3 & -2.287 & 3 & -2.356 & 3 \\
\hline VAR & -2.890 & 7 & -3.144 & 7 & -3.459 & 7 & -3.608 & 7 & -3.596 & 7 \\
\hline
\end{tabular}

$h$ denotes forecast horizon.

Source: calculated by the author.

Surprisingly, the IG-MSF-SBEKK model fits the predicted data worse (in terms of the average log predictive score) than the IG-MSF and LNMSF ones. Both of the latter specifications used one latent process common to all the conditional variances and covariances. This assumption of common dynamics led to constant conditional correlations. While comparing the average log predictive score for the LN-MSF and IG-MSF models, the author found that the inverted gamma innovations in the autoregressive specification for the latent process were outperformed by 
log-normal ones. However, the pure SBEKK-type models in most cases ranked in the reverse order: the IG-SBEKK ( $\mathrm{t}-\mathrm{SBEKK}$ ) model is better than the LN-SBEKK one.

Table 4. The average log-predictive scores and ranks obtained for the first forecasting subperiod: 3 September 2019-11March 2020

\begin{tabular}{|l|c|c|c|c|c|c|c|c|c|c|}
\hline \multicolumn{1}{|c|}{ Model } & $h=1$ & rank & $h=2$ & rank & $h=3$ & rank & $h=4$ & rank & $h=5$ & rank \\
\hline $\begin{array}{l}\text { LN-MSF- } \\
\text { SBEKK }\end{array}$ & $\mathbf{- 0 . 4 2 4}$ & $\mathbf{1}$ & $\mathbf{- 0 . 8 8 1}$ & $\mathbf{1}$ & $\mathbf{- 1 . 1 9 4}$ & $\mathbf{1}$ & $\mathbf{- 1 . 3 8 9}$ & $\mathbf{1}$ & $\mathbf{- 1 . 5 3 9}$ & $\mathbf{1}$ \\
\hline $\begin{array}{l}\text { IG-MSF- } \\
\text { SBEKK }\end{array}$ & -0.472 & 6 & -0.946 & 6 & -1.251 & 6 & -1.451 & 6 & -1.610 & 6 \\
\hline LN-SBEKK & -0.443 & 3 & -0.930 & 5 & -1.230 & 4 & -1.435 & 4 & -1.584 & 4 \\
\hline $\begin{array}{l}\text { IG-SBEKK } \\
\text { (t-SBEKK) }\end{array}$ & -0.442 & 2 & -0.926 & 4 & -1.233 & 5 & -1.444 & 5 & -1.606 & 5 \\
\hline LN-MSF & -0.447 & 4 & -0.914 & 2 & -1.222 & 2 & -1.420 & 2 & -1.570 & 2 \\
\hline IG-MSF & -0.448 & 5 & -0.916 & 3 & -1.223 & 3 & -1.426 & 3 & -1.572 & 3 \\
\hline VAR & -0.516 & 7 & -1.010 & 7 & -1.328 & 7 & -1.530 & 7 & -1.676 & 7 \\
\hline \hline \multicolumn{1}{|c|}{ Model } & $h=6$ & rank & $h=7$ & rank & $h=8$ & rank & $h=9$ & rank & $h=10$ & rank \\
\hline $\begin{array}{l}\text { LN-MSF- } \\
\text { SBEKK }\end{array}$ & $\mathbf{- 1 . 6 6 2}$ & $\mathbf{1}$ & $-\mathbf{- 1 . 7 8 1}$ & $\mathbf{1}$ & $\mathbf{- 1 . 8 9 2}$ & $\mathbf{1}$ & $\mathbf{- 1 . 9 6 2}$ & $\mathbf{1}$ & $\mathbf{- 2 . 0 1 1}$ & $\mathbf{1}$ \\
\hline $\begin{array}{l}\text { IG-MSF- } \\
\text { SBEKK }\end{array}$ & -1.735 & 6 & -1.858 & 5 & -1.957 & 4 & -2.033 & 4 & -2.086 & 4 \\
\hline LN-SBEKK & -1.721 & 4 & -1.859 & 6 & -1.982 & 6 & -2.050 & 6 & -2.092 & 5 \\
\hline $\begin{array}{l}\text { IG-SBEKK } \\
\text { (t-SBEKK) }\end{array}$ & -1.722 & 5 & -1.850 & 4 & -1.966 & 5 & -2.049 & 5 & -2.097 & 6 \\
\hline LN-MSF & -1.694 & 2 & -1.827 & 2 & -1.922 & 2 & -2.009 & 2 & -2.045 & 2 \\
\hline IG-MSF & -1.698 & 3 & -1.827 & 3 & -1.941 & 3 & -2.012 & 3 & -2.063 & 3 \\
\hline VAR & -1.800 & 7 & -1.918 & 7 & -2.062 & 7 & -2.150 & 7 & -2.161 & 7 \\
\hline
\end{tabular}

$h$ denotes forecast horizon.

Source: calculated by the author.

Turning attention to the energy score, one can see that the previous conclusion (based on the average log-predictive score) that the LN-MSF-SBEKK model outperformed the other models holds for the whole forecasting period considered (3 September 2019-2 September 2020 as well as for the subperiod 12 March 2020-2 September 2020. In the case of these two forecasting periods, the rank correlation coefficients were large and positive, see Table 8. Table 6 and Figure 3 also confirm superiority of the LN-MSF-SBEKK model in the period: 3 September 2019-2 September 2020. For periods containing the lockdown crisis the first four positions in the rank were occupied by the LN-MSF-SBEKK, IG-MSF-SBEKK, LN-MSF and IG-MSF models. The imposition of zero restrictions on $\varphi$ led 
Table 5. The average log-predictive scores and ranks obtained for the second forecasting subperiod: 12 March 2020-2 September 2020

\begin{tabular}{|l|c|c|c|c|c|c|c|c|c|c|}
\hline \multicolumn{1}{|c|}{ Model } & $h=1$ & rank & $h=2$ & rank & $h=3$ & rank & $h=4$ & rank & $h=5$ & rank \\
\hline $\begin{array}{l}\text { LN-MSF- } \\
\text { SBEKK }\end{array}$ & -0.888 & 3 & $\mathbf{- 1 . 3 5 5}$ & $\mathbf{1}$ & $\mathbf{- 1 . 5 9 7}$ & $\mathbf{1}$ & $\mathbf{- 1 . 7 8 3}$ & $\mathbf{1}$ & $\mathbf{- 1 . 9 3 6}$ & $\mathbf{1}$ \\
\hline $\begin{array}{l}\text { IG-MSF- } \\
\text { SBEKK }\end{array}$ & -0.974 & 4 & -1.449 & 4 & -1.645 & 4 & -1.840 & 4 & -2.006 & 4 \\
\hline LN-SBEKK & -1.017 & 6 & -1.494 & 6 & -1.754 & 6 & -1.963 & 6 & -2.176 & 6 \\
\hline $\begin{array}{l}\text { IG-SBEKK } \\
\text { (t-SBEKK) }\end{array}$ & -1.010 & 5 & -1.482 & 5 & -1.734 & 5 & -1.949 & 5 & -2.102 & 5 \\
\hline LN-MSF & $\mathbf{- 0 . 8 8 2}$ & $\mathbf{1}$ & -1.360 & 2 & -1.602 & 2 & -1.803 & 2 & -1.959 & 2 \\
\hline IG-MSF & -0.884 & 2 & -1.360 & 3 & -1.604 & 3 & -1.808 & 3 & -1.967 & 3 \\
\hline VAR & -1.266 & 7 & -1.817 & 7 & -2.212 & 7 & -2.588 & 7 & -3.083 & 7 \\
\hline \hline \multicolumn{1}{|c|}{ Model } & $h=6$ & rank & $h=7$ & rank & $h=8$ & rank & $h=9$ & rank & $h=10$ & rank \\
\hline $\begin{array}{l}\text { LN-MSF- } \\
\text { SBEKK }\end{array}$ & $\mathbf{- 2 . 0 8 1}$ & $\mathbf{1}$ & $\mathbf{- 2 . 2 0 2}$ & $\mathbf{1}$ & $\mathbf{- 2 . 3 1 4}$ & $\mathbf{1}$ & $\mathbf{- 2 . 4 0 7}$ & $\mathbf{1}$ & $\mathbf{- 2 . 4 9 3}$ & $\mathbf{1}$ \\
\hline $\begin{array}{l}\text { IG-MSF- } \\
\text { SBEKK }\end{array}$ & -2.223 & 4 & -2.319 & 4 & -2.471 & 4 & -2.594 & 4 & -2.662 & 4 \\
\hline LN-SBEKK & -2.445 & 6 & -2.591 & 6 & -2.782 & 6 & -2.934 & 6 & -3.065 & 6 \\
\hline $\begin{array}{l}\text { IG-SBEKK } \\
\text { (t-SBEKK) }\end{array}$ & -2.317 & 5 & -2.515 & 5 & -2.577 & 5 & -2.824 & 5 & -2.942 & 5 \\
\hline LN-MSF & -2.138 & 2 & -2.255 & 2 & -2.389 & 2 & -2.484 & 2 & -2.577 & 2 \\
\hline IG-MSF & -2.151 & 3 & -2.267 & 3 & -2.406 & 3 & -2.522 & 3 & -2.601 & 3 \\
\hline VAR & -3.871 & 7 & -4.228 & 7 & -4.672 & 7 & -4.852 & 7 & -4.800 & 7 \\
\hline
\end{tabular}

$h$ denotes forecast horizon.

Source: calculated by the author.

to a substantial deterioration in forecast performance. In fact, the pure SBEKK models took the last two positions among the models with conditional heteroscedasticity. A different result was obtained for the period 3 September 2019-11 March 2020 (characterized by relatively low volatility), in which the IG-MSF-SBEKK model was clearly superior to the other specifications at all the forecast horizons. For $h=2, \ldots, 10$ the second position was occupied by the IG-SBEKK model, and the fourth position by the LN-MSF-SBEKK one. As one can see from Table 8, for the subperiod 3 September 2019-11 March 2020 the rank correlation coefficients were negative. However, the differences between the average energy scores seem to be within the limits of the numerical error. 
Table 6. The average energy score and ranks obtained for the whole forecasting period:

3 September 2019-2 September 2020

$\mathrm{Nr}$ 18(24)

\begin{tabular}{|l|c|c|c|c|c|c|c|c|c|c|}
\hline \multicolumn{1}{|c|}{ Model } & $h=1$ & rank & $h=2$ & rank & $h=3$ & rank & $h=4$ & rank & $h=5$ & rank \\
\hline $\begin{array}{l}\text { LN-MSF- } \\
\text { SBEKK }\end{array}$ & $\mathbf{2 5 0 . 1 4 5}$ & $\mathbf{1}$ & $\mathbf{2 5 0 . 1 2 5}$ & $\mathbf{1}$ & $\mathbf{2 5 0 . 1 0 8}$ & $\mathbf{1}$ & $\mathbf{2 5 0 . 0 9 1}$ & $\mathbf{1}$ & $\mathbf{2 5 0 . 0 8 1}$ & $\mathbf{1}$ \\
\hline $\begin{array}{l}\text { IG-MSF- } \\
\text { SBEKK }\end{array}$ & 250.147 & 3 & 250.128 & 2 & 250.112 & 2 & 250.095 & 2 & 250.086 & 2 \\
\hline LN-SBEKK & 250.149 & 6 & 250.133 & 7 & 250.118 & 7 & 250.104 & 7 & 250.097 & 7 \\
\hline $\begin{array}{l}\text { IG-SBEKK } \\
\text { (t-SBEKK) }\end{array}$ & 250.149 & 5 & 250.131 & 5 & 250.116 & 5 & 250.102 & 5 & 250.094 & 5 \\
\hline LN-MSF & 250.147 & 4 & 250.129 & 4 & 250.114 & 4 & 250.099 & 4 & 250.091 & 4 \\
\hline IG-MSF & 250.146 & 2 & 250.129 & 3 & 250.113 & 3 & 250.098 & 3 & 250.089 & 3 \\
\hline VAR & 250.149 & 7 & 250.132 & 6 & 250.117 & 6 & 250.102 & 6 & 250.094 & 6 \\
\hline \hline Model & $h=6$ & rank & $h=7$ & rank & $h=8$ & rank & $h=9$ & rank & $h=10$ & rank \\
\hline $\begin{array}{l}\text { LN-MSF- } \\
\text { SBEKK }\end{array}$ & $\mathbf{2 5 0 . 0 7 2}$ & $\mathbf{1}$ & $\mathbf{2 5 0 . 0 5 7}$ & $\mathbf{1}$ & $\mathbf{2 5 0 . 0 4 0}$ & $\mathbf{1}$ & $\mathbf{2 5 0 . 0 2 5}$ & $\mathbf{1}$ & $\mathbf{2 5 0 . 0 1 9}$ & $\mathbf{1}$ \\
\hline $\begin{array}{l}\text { IG-MSF- } \\
\text { SBEKK }\end{array}$ & 250.078 & 2 & 250.064 & 2 & 250.049 & 2 & 250.033 & 2 & 250.030 & 2 \\
\hline LN-SBEKK & 250.091 & 7 & 250.080 & 7 & 250.068 & 7 & 250.057 & 7 & 250.050 & 7 \\
\hline $\begin{array}{l}\text { IG-SBEKK } \\
\text { (t-SBEKK) }\end{array}$ & 250.088 & 6 & 250.076 & 6 & 250.063 & 6 & 250.052 & 6 & 250.045 & 6 \\
\hline LN-MSF & 250.084 & 4 & 250.072 & 4 & 250.059 & 4 & 250.048 & 4 & 250.040 & 4 \\
\hline IG-MSF & 250.082 & 3 & 250.071 & 3 & 250.057 & 3 & 250.046 & 3 & 250.038 & 3 \\
\hline VAR & 250.088 & 5 & 250.076 & 5 & 250.063 & 5 & 250.051 & 5 & 250.044 & 5 \\
\hline
\end{tabular}

Source: calculated by the author.

Table 7. The average energy score and ranks obtained for the whole forecasting period: 3 September 2019-11 March 2020

\begin{tabular}{|l|c|c|c|c|c|c|c|c|c|c|}
\hline \multicolumn{1}{|c|}{ Model } & $h=1$ & rank & $h=2$ & rank & $h=3$ & rank & $h=4$ & rank & $h=5$ & rank \\
\hline \multicolumn{1}{|c}{1} & 2 & 3 & 4 & 5 & 6 & 7 & 8 & 9 & 10 & 11 \\
\hline $\begin{array}{l}\text { LN-MSF- } \\
\text { SBEKK }\end{array}$ & 247.945 & 4 & 247.932 & 4 & 247.928 & 4 & 247.923 & 4 & 247.923 & 4 \\
\hline $\begin{array}{l}\text { IG-MSF- } \\
\text { SBEKK }\end{array}$ & $\mathbf{2 4 7 . 9 4 4}$ & $\mathbf{1}$ & $\mathbf{2 4 7 . 9 3 1}$ & $\mathbf{1}$ & $\mathbf{2 4 7 . 9 2 7}$ & $\mathbf{1}$ & $\mathbf{2 4 7 . 9 2 1}$ & $\mathbf{1}$ & $\mathbf{2 4 7 . 9 2 1}$ & $\mathbf{1}$ \\
\hline LN-SBEKK & 247.945 & 6 & 247.933 & 5 & 247.930 & 6 & 247.925 & 6 & 247.925 & 5 \\
\hline $\begin{array}{l}\text { IG-SBEKK } \\
\text { (t-SBEKK) }\end{array}$ & 247.945 & 3 & 247.932 & 2 & 247.928 & 2 & 247.922 & 2 & 247.923 & 2 \\
\hline LN-MSF & 247.945 & 7 & 247.934 & 7 & 247.930 & 7 & 247.925 & 7 & 247.926 & 7 \\
\hline IG-MSF & 247.945 & 5 & 247.933 & 6 & 247.930 & 5 & 247.925 & 5 & 247.925 & 6 \\
\hline VAR & 247.944 & 2 & 247.932 & 3 & 247.928 & 3 & 247.923 & 3 & 247.923 & 3 \\
\hline
\end{tabular}




\begin{tabular}{|l|c|c|c|c|c|c|c|c|c|c|}
\hline \multicolumn{1}{|c|}{1} & 2 & 3 & 4 & 5 & 6 & 7 & 8 & 9 & 10 & 11 \\
\hline \multicolumn{1}{|c}{ Model } & $h=6$ & rank & $h=7$ & rank & $h=8$ & rank & $h=9$ & rank & $h=10$ & rank \\
\hline $\begin{array}{l}\text { LN-MSF- } \\
\text { SBEKK }\end{array}$ & 247.926 & 4 & 247.926 & 4 & 247.923 & 4 & 247.923 & 4 & 247.920 & 4 \\
\hline $\begin{array}{l}\text { IG-MSF- } \\
\text { SBEKK }\end{array}$ & $\mathbf{2 4 7 . 9 2 3}$ & $\mathbf{1}$ & $\mathbf{2 4 7 . 9 2 3}$ & $\mathbf{1}$ & $\mathbf{2 4 7 . 9 1 9}$ & $\mathbf{1}$ & $\mathbf{2 4 7 . 9 1 8}$ & $\mathbf{1}$ & $\mathbf{2 4 7 . 9 1 4}$ & $\mathbf{1}$ \\
\hline LN-SBEKK & 247.928 & 6 & 247.929 & 6 & 247.926 & 6 & 247.927 & 6 & 247.924 & 6 \\
\hline $\begin{array}{l}\text { IG-SBEKK } \\
\text { (t-SBEKK) }\end{array}$ & 247.925 & 2 & 247.926 & 2 & 247.922 & 2 & 247.922 & 2 & 247.919 & 2 \\
\hline LN-MSF & 247.929 & 7 & 247.930 & 7 & 247.927 & 7 & 247.928 & 7 & 247.925 & 7 \\
\hline IG-MSF & 247.928 & 5 & 247.929 & 5 & 247.926 & 5 & 247.927 & 5 & 247.924 & 5 \\
\hline VAR & 247.926 & 3 & 247.926 & 3 & 247.922 & 3 & 247.923 & 3 & 247.919 & 3 \\
\hline
\end{tabular}

Source: calculated by the author.

Table 8. Rank correlation coefficients for the average log-predictive score and the average energy score

\begin{tabular}{|l|c|c|c|c|c|c|c|c|c|c|}
\hline Forecasting period & $h=1$ & $h=2$ & $h=3$ & $h=4$ & $h=5$ & $h=6$ & $h=7$ & $h=8$ & $h=9$ & $h=10$ \\
\hline $\begin{array}{l}\text { 3September 2019 } \\
\text {-2September 2020 }\end{array}$ & 0.89 & 0.82 & 0.82 & 0.82 & 0.82 & 0.75 & 0.75 & 0.75 & 0.75 & 0.75 \\
\hline $\begin{array}{l}\text { 3September 2019 } \\
-1 \text { March 2020 }\end{array}$ & -0.39 & -0.57 & -0.64 & -0.64 & -0.68 & -0.64 & -0.32 & -0.29 & -0.29 & -0.43 \\
\hline $\begin{array}{l}\text { 12March 2020 } \\
\text {-2September 2020 }\end{array}$ & 0.86 & 0.93 & 0.82 & 0.82 & 0.75 & 0.75 & 0.75 & 0.75 & 0.75 & 0.75 \\
\hline
\end{tabular}

Source: calculated by the author.

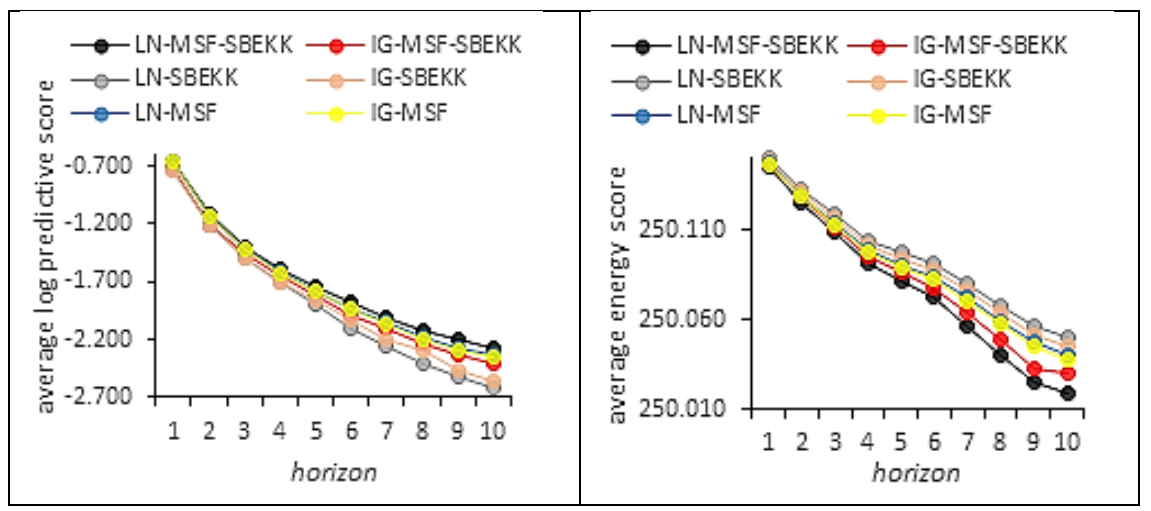

Fig. 3. The average log-predictive scores (positive oriented) and the average energy scores (negative oriented) for the whole forecasting period (3 September 2019-2 September 2020)

Source: calculated by the author. 


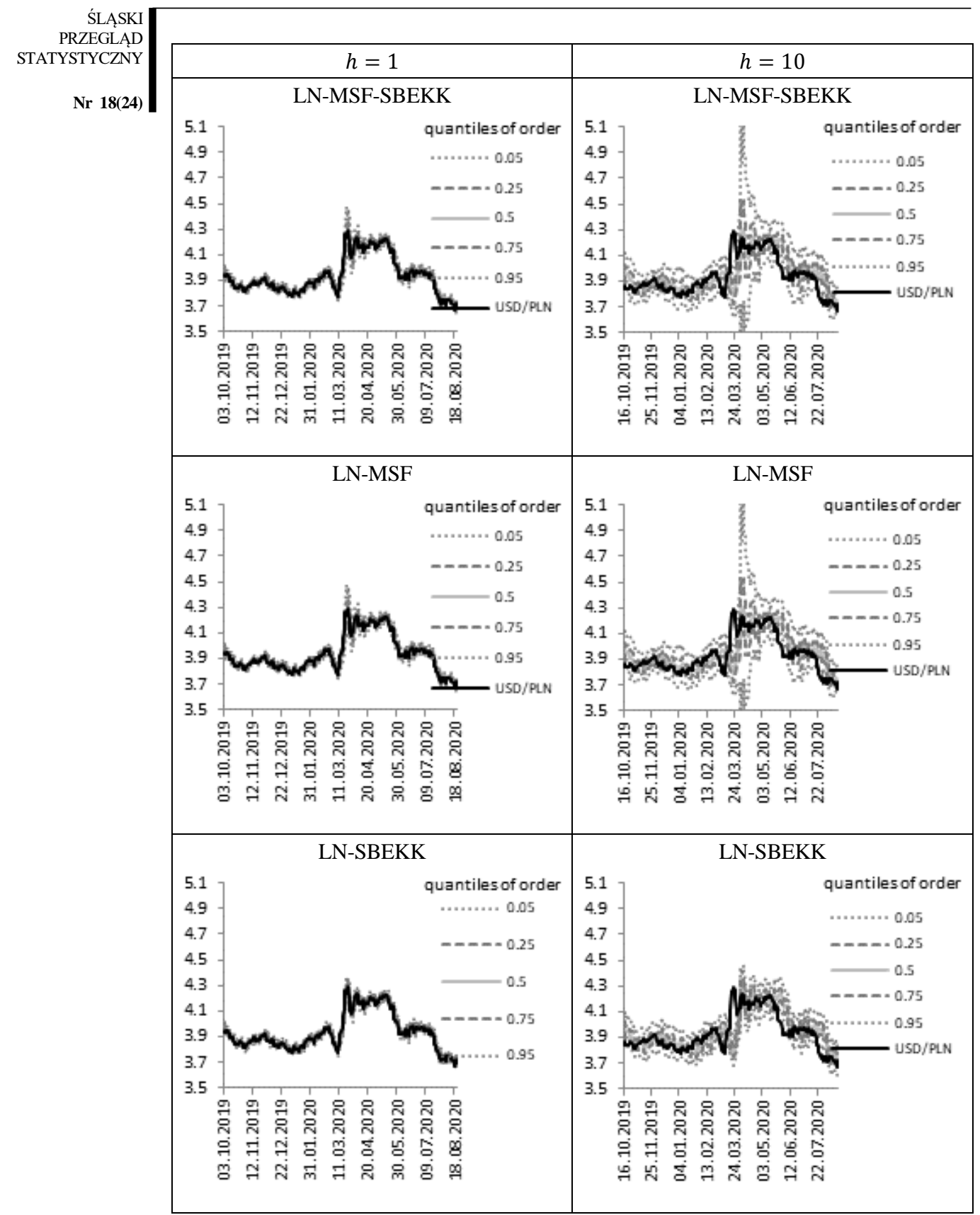

Fig. 4. Quantiles of predictive distributions for USD/PLN Source: calculated by the author. 


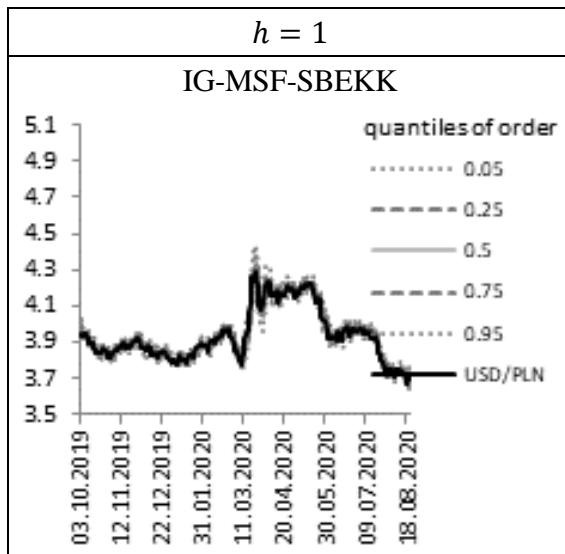

ŚLĄSKI

PRZEGLAĊ

STATYSTYCZNY

Nr 18(24)
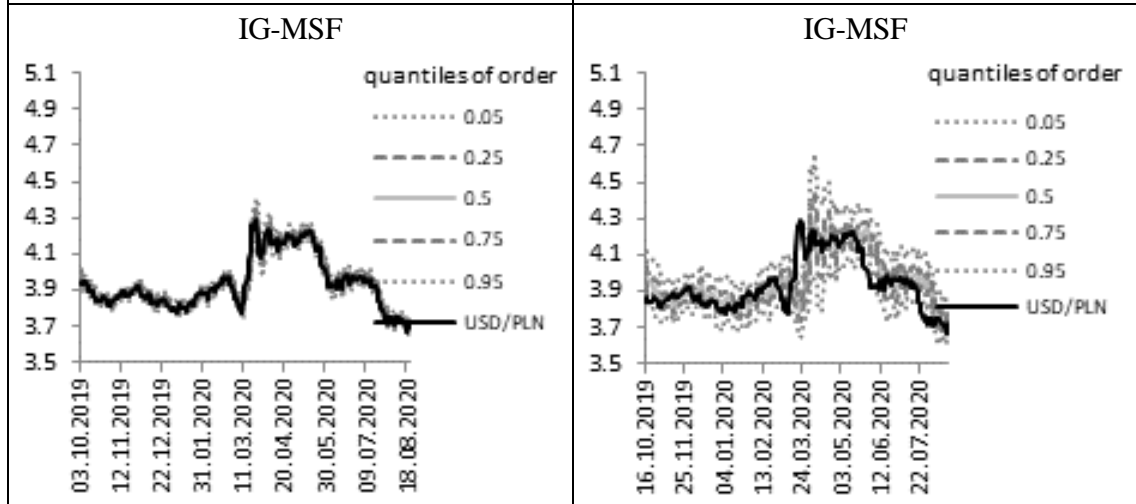

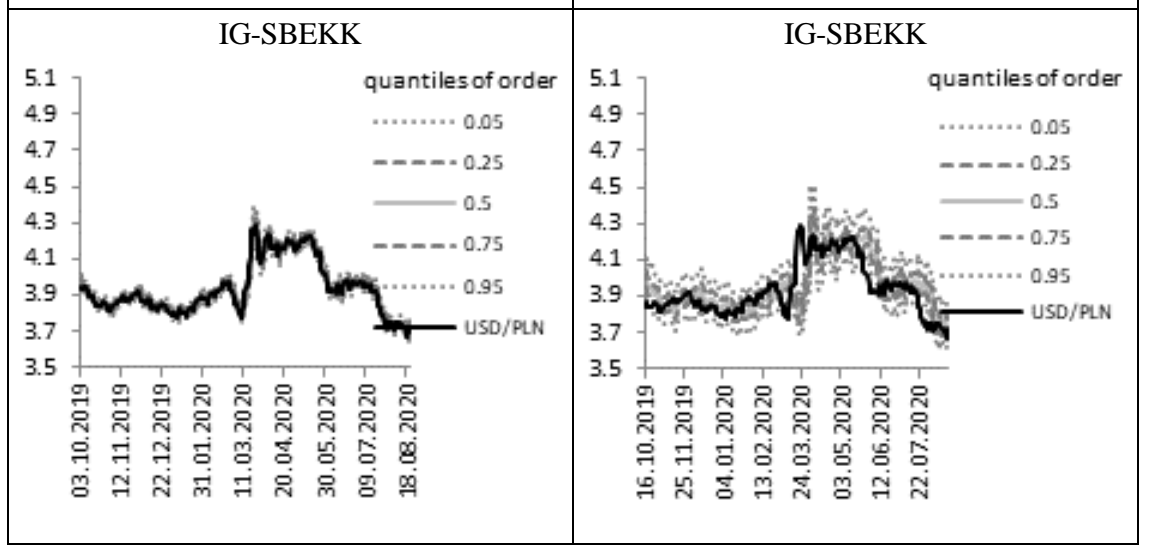

Fig. 5. Quantiles of predictive distributions for USD/PLN Source: calculated by the author. 
As expected, the dispersion of the predictive distributions (measured by e.g. the interquartile range) increased with the forecast horizon. In fact, for the USD/PLN and EUR/PLN exchange rates, the average interquartile range for the ten-day forecast horizon was about three times larger than for the one-day horizon. In turn, for the GBP/PLN the average interquartile range for the ten-day forecast horizon was about eight times larger than for the one-day horizon. To illustrate how the predictive distribution changed along with the increasing forecast horizon, the author presents (in Figures 4 and 5) quantiles of the predictive distributions for $h=1$ and $h=10$, obtained in the models considered. The predictive distributions for $h=10$ were much more spread than those for $h=1$. Moreover, the accuracy of forecasts with $h=10$ was not quite satisfactory - a few realized data were outside of the $90 \%$ confidence intervals.

As seen from Figures 4 and 5, and while analysing the predictive quantiles, the predictive distributions obtained in the LN-MSF-SBEKK model turned out to be the most dispersed - this dispersion was measured by interquartile ranges and the difference between the quantile of order 0.05 and of order 0.95. The LN-SBEKK and IG-BEKK models are characterized by the least spread of predictive distributions. The differences in the predictive distributions among the models influenced the values of the predictive Bayes factors, log-predictive scores and energy scores.

\section{Conclusion}

The paper compared the predictive ability of the LN-MSF-SBEKK and IGMSF-SBEKK models (and their simplifications) in the context of modelling the main exchange rates for PLN. According to the results obtained on the basis of the average log-predictive score and energy score, the author concluded that for most of the forecast horizons considered, the LN-MSF-SBEKK specification outperformed the IG-MSF-SBEKK one. As measured by the average log-predictive score, the predictive performance of the stochastic volatility models with log-normal innovations dominated that of the SV ones with inverted gamma innovations.

The results can be sensitive to the prior assumptions regarding the model parameters, especially the parameters related to the latent process: $\varphi, \sigma^{2}$ and $v$. In this paper the author did not carry out the study of the sensitivity of these results to a priori assumptions. It is worth mentioning that under the author's prior assumptions about the parameters of latent processes, the marginal variances of the two latent processes (based on lognormal and inverted gamma innovations) had similar prior distributions. In this sense, the prior distributions of the basic parameters in the LN-MSF- 
SBEKK and IG-MSF-SBEKK models were treated as coherent (see:

Osiewalski and Pajor, 2019). The application of this analysis to alternative conditional covariance assumptions can provide a useful direction for future research.

\section{References}

Baba, Y., Engle, R., Kraft, D., and Kroner, K. (1989). Multivariate simultaneous generalised ARCH (Manuscript). University of California at San Diego, Department of Economics.

Bauwens, L., Laurent, S., and Rombouts, J. V. K. (2006). Multivariate GARCH models: A survey. Journal of Applied Econometrics, (21), 79-109.

Bernardo, J. M., and Smith, A. F. M. (1994). Bayesian theory. New York: John Wiley and Sons.

Dawid, A. P., and Musio, M. (2014). Theory and applications of proper scoring rules. Metron, (72), 169-183.

Dawid, A. P., and Musio, M. (2015). Bayesian model selection based on proper scoring rules. Bayesian Analysis, 10(2), 479-499.

Geweke, J. (2005). Contemporary Bayesian econometrics and statistics. Wiley Series in Probability and Statistics. New York: Wiley - Interscience [John Wiley and Sons], Hoboken.

Geweke, J., and Amisano, G. (2010). Comparing and evaluating Bayesian predictive distributions of asset returns. International Journal of Forecasting, 26(2), 216-230.

Gneiting, T., and Raftery, A. E. (2007). Strictly proper scoring rules, prediction, and estimation. Journal of the American Statistical Association, (102), 359-378.

Kass, R. E., and Raftery, A. E. (1995). Bayes factors. Journal of the American Statistical Association, 90(430), 773-795.

Osiewalski, J. (2009). New hybrid models of multivariate volatility (a Bayesian perspective). Przegląd Statystyczny (Statistical Review), (56), 15-22.

Osiewalski, J., and Pajor, A. (2009). Bayesian analysis for hybrid MSF-SBEKK models of multivariate volatility. Central European Journal of Economic Modelling and Econometrics, (1), 179-202.

Osiewalski, J., and Pajor, A. (2018). A hybrid MSV-MGARCH generalisation of the $t$-MGARCH model. In M. Papież and S. Śmiech (Eds.), The 12th Professor Aleksander Zelias International Conference on Modelling and Forecasting of Socio-Economic Phenomena: Conference Proceedings (pp. 345-354). Cracow: Foundation of the Cracow University of Economics.

Osiewalski, J., and Pajor, A. (2019). On Sensitivity of Inference in Bayesian MSFMGARCH Models. Central European Journal of Economic Modelling and Econometrics, 11(3), 173-197.

Pajor, A. (2020). MCMC method for the IG-MSF-SBEKK model. In B. Ciałowicz (eds.), Quantitative methods in the contemporary issues of economics (pp. 77-89). KrakówLegionowo: edu-Libri. Retrieved from http://matematyka.uek.krakow.pl/SEMPP 2020/Quantitative-methods_e-pdf_v3.pdf

Pajor, A., and Wróblewska, J. (2017). VEC-MSF models in Bayesian analysis of short and long-run relationships. Studies in Nonlinear Dynamics and Econometrics, 21(3), 1-22. 
Székely, G. J., and Rizzo, M. L. (2013). Energy statistics: A class of statistics based on distances. Journal of Statistical Planning and Inference, (143), 1249-1272.

Nr 18(24)

Tsay, R. S. (2005). Analysis of financial time series (2nd edition). New York: Wiley.

Wróblewska, J., and Pajor, A. (2019). One-period joint forecasts of Polish inflation, unemployment and interest rates using Bayesian VEC-MSF models. Central European Journal of Economic Modelling and Econometrics, 11(1), 23-45.

\section{ODWRÓCONE GAMMA A LOGARYTMICZNO-NORMALNE INNOWACJE W MODELACH MSF-SBEKK W PROGNOZOWANIU WYBRANYCH POLSKICH KURSÓW WALUTOWYCH}

Streszczenie: Celem badania jest porównanie własności prognostycznych dwóch klas modeli MSF-SBEKK różniących się postacią procesu ukrytego. W klasie pierwszej innowacje w strukturze autoregresyjnej pierwszego rzędu dla logarytmów naturalnych zmiennych ukrytych mają rozkład logarytmiczno-normalny, w klasie drugiej zaś innowacje te mają odwrócony rozkład gamma. Porównanie modeli z wykorzystaniem predyktywnego czynnika Bayesa, a także metod scoringowych dokonywane jest w kontekście prognozowania wybranych kursów walutowych: USD/PLN, EUR/PLN i GBP/PLN w okresie obejmującym kryzys wywołany pandemią COVID-19. Wyniki empiryczne pokazały, że dla większości branych pod uwagę horyzontów prognozy modele z innowacjami o rozkładzie logarytmiczno-normalnym mają lepsze własności predyktywne niż modele z innowacjami o rozkładzie odwróconym gamma.

Słowa kluczowe: model zmienności stochastycznej, prognozowanie, predyktywny czynnik Bayesa. 